\title{
Should clopidogrel be discontinued before coronary artery bypass grafting for patients with acute coronary syndrome? A systematic review and meta-analysis
}

\author{
Christopher Cao, MBBS, a,b,c Praveen Indraratna, MBBS, ${ }^{a}$ Su C. Ang, MBBS, ${ }^{a}$ Con Manganas, MBBS, \\ John Park, MBBS, ${ }^{\mathrm{a}}$ Paul G. Bannon, MBBS, PhD, ${ }^{\mathrm{a}, \mathrm{b}, \mathrm{d}}$ and Tristan D. Yan, MBBS, MD, PhD ${ }^{\mathrm{a}, \mathrm{b}, \mathrm{d}}$
}

Objective: Patients presenting with acute coronary syndrome (ACS) are treated with dual antiplatelet agents,
including aspirin and clopidogrel, to prevent mortality and recurrent ischemia. However, those who require
coronary artery bypass grafting (CABG) could have increased postoperative bleeding and bleeding-related
adverse outcomes. The current guidelines on clinical management differ significantly. The present
meta-analysis examined the evidence for clopidogrel in the treatment of patients presenting with ACS requiring
CABG, with a focus on the timing of medication cessation before surgery.

Methods: A systematic review of 9 electronic databases was performed to identify all relevant studies with comparable outcomes for patients with ACS treated with clopidogrel before CABG. The endpoints included reoperation, major bleeding, mortality, and a composite endpoint of mortality and recurrent myocardial infarction.

Results: Five relevant studies were identified according to the predefined selection criteria. Patients who had received clopidogrel had a significantly lower incidence of composite endpoints than those who had not. However, patients who underwent $\mathrm{CABG}<5$ days after the last dose of clopidogrel had a significantly greater incidence of reoperation, major bleeding, and combined adverse outcomes than those who had had a washout period $>5$ days.

Conclusions: The results from the present meta-analysis suggest that patients who present with ACS should be treated with dual antiplatelet therapy, including clopidogrel. However, for patients subsequently referred for CABG, a minimum washout period of 5 days should be observed to minimize perioperative bleeding and bleeding-related complications, unless emergency indications exist. These results differ from those of previous studies and guidelines. (J Thorac Cardiovasc Surg 2014;148:3092-8)

See related commentary on pages 3099-100.

Acute coronary syndrome (ACS) is commonly associated with atherosclerotic plaque rupture, which can be followed by platelet activation and subsequent coronary occlusion due to thrombus formation. To prevent potentially fatal sequelae, antiplatelet medications are routinely administered to patients presenting with ACS. However, the prescription of aspirin before coronary artery bypass grafting (CABG) has

From the Systematic Review Unit, ${ }^{a}$ Collaborative Research (CORE) Group, Macquarie University, Sydney, Australia; Baird Institute for Applied Heart and Lung Surgical Research, ${ }^{\text {b }}$ Sydney, Australia; Department of Cardiothoracic Surgery, ${ }^{c}$ St George Hospital, Sydney, Australia; and Department of Cardiothoracic Surgery, ${ }^{\mathrm{d}}$ Royal Prince Alfred Hospital, Sydney, Australia.

Disclosures: Authors have nothing to disclose with regard to commercial support.

Received for publication Dec 23, 2013; revisions received March 25, 2014; accepted for publication April 17, 2014; available ahead of print June 20, 2014.

Address for reprints: Christopher Cao, MBBS, Department of Cardiothoracic

Surgery, St George Hospital, Sydney, NSW 2011, Australia (E-mail: drchriscao@gmail.com).

$0022-5223 / \$ 36.00$

Copyright (c) 2014 by The American Association for Thoracic Surgery

http://dx.doi.org/10.1016/j.jtcvs.2014.04.054 raised concerns of increased postoperative bleeding since the beginning of cardiac surgery in the late 1970s. ${ }^{1,2}$ With pharmacologic evolution and development, an exponential growth has occurred in the prescription of antiplatelet agents during the past decade. Some of the most commonly prescribed modern antiplatelet agents function as $\mathrm{P}_{2} \mathrm{Y}_{12}$ adenosine diphosphate receptor antagonists, including clopidogrel, prasugrel, and ticagrelor. Despite being one of the most prevalent drugs internationally, the prescribing pattern of clopidogrel for patients presenting with ACS has remained heterogeneous in clinical practice, in particular, for those who might require subsequent surgical revascularization.

At the crux of the dilemma concerning antiplatelet therapy in relation to CABG is the risk of postoperative bleeding and bleeding-related complications weighed against the potential benefits of the mortality and ischemic events prevented by preoperative anticoagulation. Proponents of aggressive dual antiplatelet therapy have emphasized the benefits derived from reduced mortality and recurrent myocardial infarction at no additional risk to perioperative bleeding. ${ }^{3,4}$ However, others have cautioned against this regimen for patients undergoing 


\section{Abbreviations and Acronyms \\ ACS = acute coronary syndrome \\ $\mathrm{CABG}=$ coronary artery bypass grafting \\ CI $=$ confidence interval \\ CRUSADE $=$ Can Rapid Risk Stratification of \\ Unstable Angina Patients Suppress \\ Adverse Outcomes With Early \\ Implementation of the ACC/AHA \\ [American College of Cardiology/ \\ American Heart Association] \\ Guidelines \\ DISPERSE-2 $=$ Clopidogrel in Non-ST-Segment \\ Elevation Myocardial Infarction-2 \\ OR $=$ odds ratio \\ PLATO $=$ PLATelet inhibition and patient \\ Outcomes \\ RCT $=$ randomized controlled trial}

CABG, citing clinical and economic outcomes. ${ }^{5}$ Despite the vast quantity of research, major disagreements remain owing to the conflicting data. Furthermore, the guidelines from various international medical associations have presented different recommendations, further hindering the decision-making process for clinicians. ${ }^{6-10} \mathrm{We}$ examined the current clinical evidence for the use of clopidogrel in the treatment of patients presenting with ACS and requiring CABG, with a specific focus on the timing of medication cessation before CABG.

\section{METHODS}

\section{Literature Search Strategy}

Electronic searches were performed on OVID Medline, EMBASE, ACP Journal Club, Database of Abstracts of Reviews of Effects, Cochrane Database of Systematic Reviews, Health Technology Assessment, Cochrane Methodology Register, NHS Economic Evaluation Database, and Cochrane Central Register of Controlled Trials from their date of inception to March 2013. The search strategy included a combination of "clopidogrel" or "iscover" or "plavix" and "coronary artery bypass grafting" or "coronary artery surgery" or "coronary artery graft surgery" or "CABG" and "bleeding" or "haemorrhage" or "hemorrhage" as either keywords or MeSH headings. The reference lists of all retrieved studies were reviewed for additional identification of potentially relevant studies. All relevant studies identified were assessed with application of the predefined selection criteria.

\section{Selection Criteria and Data Extraction}

The selected studies for the present meta-analysis included those that provided data on comparative bleeding outcomes for patients presenting with ACS who had been treated with clopidogrel before CABG. To match comparable endpoints, only studies with data on clopidogrel cessation at $<5$ or $>5$ days before CABG were included. When institutions had published duplicate trials, only the most updated reports were included for quantitative appraisal. The primary endpoints included major bleeding, reoperation, all-cause mortality, and the composite endpoint of mortality and myocardial infarction. All publications were limited to human subjects and the English language. Abstracts, case reports, conference presentations, editorials, and expert opinions were excluded.

To standardize comparisons between the treatment groups, separate analyses were performed to compare patients who had been treated with clopidogrel within 5 days of $\mathrm{CABG}$ and those who had had a 5-day washout period. Additionally, patients who had had $>5$ days of clopidogrel clearance were compared with those who had not received clopidogrel at all. Data were extracted from the text, tables, and figures of the selected studies. Two of the investigators (P.I. and S.A.) independently reviewed each retrieved study. Discrepancies between the 2 reviewers were resolved by discussion and consensus with the senior investigators (C.C. and T.D.Y.).

\section{Statistical Analysis}

The meta-analysis was performed by combining the reported incidence of the primary endpoints. The odds ratio (OR) was used as a summary statistic. In the present meta-analysis, the results using the random effects model were presented account for the possible clinical diversity and methodologic variation among the studies. Chi-square tests were used to study the heterogeneity among the trials. The $\mathrm{I}^{2}$ statistic was used to estimate the percentage of total variation across the studies, resulting from heterogeneity rather than chance. The $\mathrm{I}^{2}$ can be calculated as $\mathrm{I}^{2}=100 \% \times(\mathrm{Q}-\mathrm{df}) / \mathrm{Q}$, with $\mathrm{Q}$ defined as Cochrane's heterogeneity statistics and $\mathrm{df}$ as the degree of freedom. An $\mathrm{I}^{2}$ value $>50 \%$ was considered substantial heterogeneity. If substantial heterogeneity was present, the possible clinical and methodologic reasons for this were explored qualitatively. Sensitivity analysis was performed by testing both fixed and random effect models. All $P$ values were 2-sided. All statistical analyses were conducted using Review Manager, version 5.1.2 (Cochrane Collaboration, Software Update, Oxford, United Kingdom).

\section{RESULTS}

\section{Quantity and Quality of Trials}

A total of 700 references were identified through the 9 electronic database searches, with 6 additional records identified through other sources. After exclusion of duplicate references, 504 potentially relevant studies were retrieved. After a detailed evaluation of these studies, 41 remained for assessment. After applying the selection criteria, 5 studies were selected for quantitative assessment and meta-analysis. ${ }^{4,5,11-13}$ Of these 5 reports, 1 was a randomized controlled trial (RCT) comparing clopidogrel until 5 days before $\mathrm{CABG}$ versus clopidogrel up to the point of surgery. ${ }^{13}$ Three studies were subgroup analyses of RCTs comparing clopidogrel versus no clopidogrel, ${ }^{4,11,12}$ and one was a large multi-institutional observational study. ${ }^{5}$ The data presented from these 5 reports included 6385 patients with coronary artery disease who had presented with ACS and subsequently underwent CABG. Of these, 2632 had been treated with clopidogrel and 3753 had not. An overview of the search strategy is presented in Figure 1, and a summary of the study characteristics is presented in Table 1.

\section{Clopidogrel Washout $>5$ Days Versus No Clopidogrel}

When the 873 patients who had been prescribed clopidogrel with a washout period of $>5$ days before 


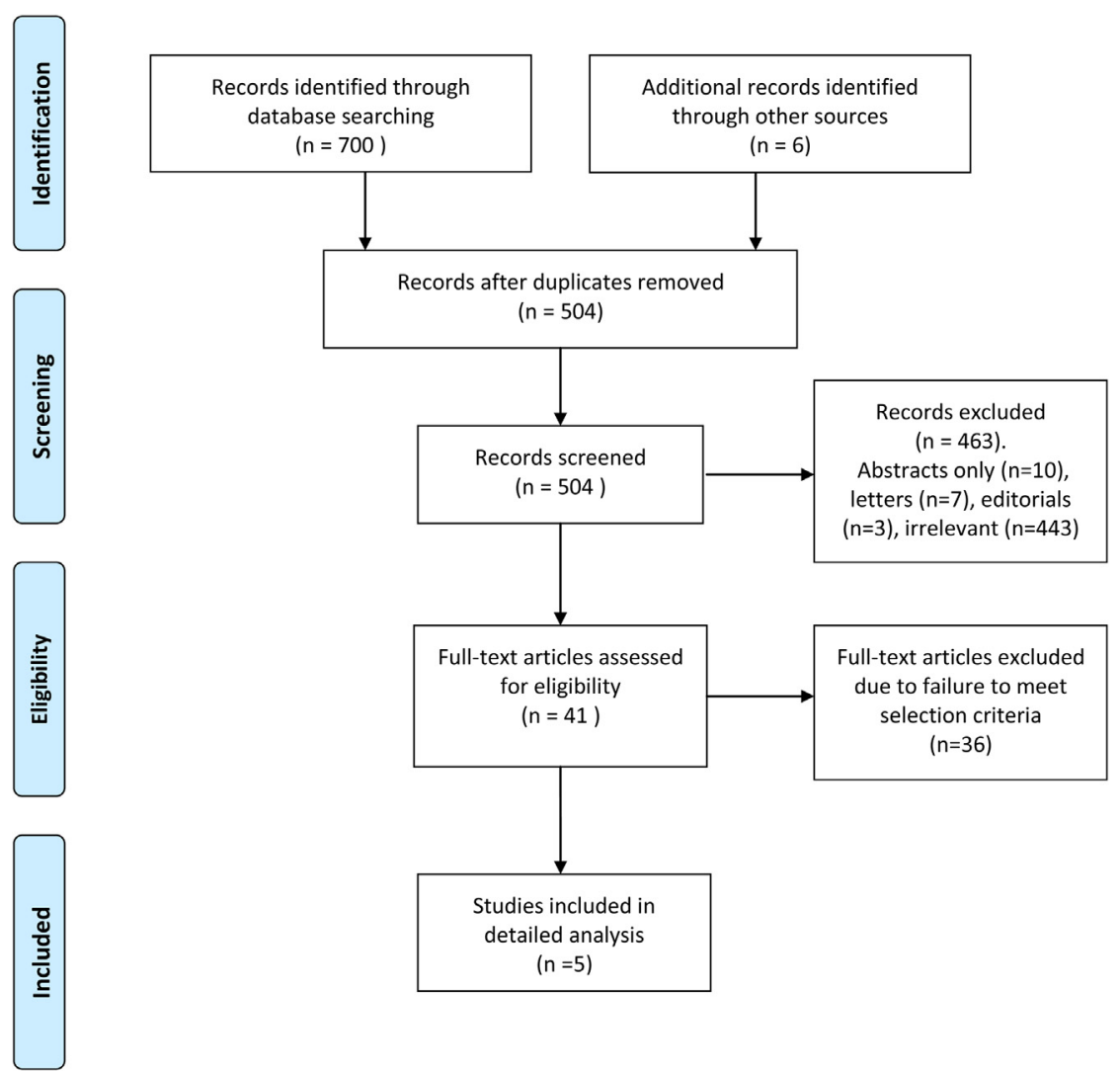

FIGURE 1. Summary of search strategy performed to identify all relevant studies for meta-analysis of clopidogrel before coronary artery bypass grafting.

CABG were compared with the corresponding 1413 patients who had not, those treated with clopidogrel demonstrated a significantly lower incidence of composite endpoints $(8.1 \%$ vs $14.1 \%$; OR, $0.60 ; 95 \%$ confidence interval $[\mathrm{CI}], 0.44-0.81 ; P=.0008 ; \mathrm{I}^{2}=0 \%$; Figure 2). The incidence of reoperation $(1.5 \%$ vs $2.3 \%$; OR, 0.51 ; $95 \% \mathrm{CI}, 0.25-1.06 ; P=.07 ; \mathrm{I}^{2}=0 \%$ ), all-cause mortality (3.3\% vs $3.9 \%$; OR, 0.86 ; $95 \%$ CI, $0.39-1.89 ; P=.70$; $\left.\mathrm{I}^{2}=21 \%\right)$, and major bleeding $(19.7 \%$ vs $32.3 \%$; OR, $0.85 ; 95 \%$ CI, $0.67-1.07 ; P=.17 ; \mathrm{I}^{2}=0 \%$ ) between these 2 treatment groups was not significantly different. Separate analyses using a fixed effect model did not alter the significant statistical findings.

\section{Clopidogrel Washout $>5$ Days Versus $<5$ Days}

Of the 2632 patients presenting with ACS included in the meta-analysis who had been prescribed clopidogrel before CABG, 1759 had been prescribed clopidogrel $<5$ days before CABG and 873 patients had had a washout period of $>5$ days before CABG. When these 2 groups were compared, patients who had $>5$ days of washout were shown to have a lower incidence of reoperation $(1.8 \%$ vs

TABLE 1. Summary of selected studies that compared bleeding outcomes after clopidogrel before CABG

\begin{tabular}{|c|c|c|c|c|c|c|c|c|c|c|}
\hline \multirow[b]{2}{*}{ Study } & \multirow[b]{2}{*}{ Study type } & \multirow{2}{*}{$\begin{array}{c}\text { Publication } \\
\text { year }\end{array}$} & \multirow{2}{*}{$\begin{array}{c}\text { Enrolling } \\
\text { period }\end{array}$} & \multirow[b]{2}{*}{ Indication } & \multirow{2}{*}{$\begin{array}{c}\text { Urgent } \\
\text { CABG }(\%)\end{array}$} & \multirow[b]{2}{*}{ OPCAG $(\%)$} & \multicolumn{2}{|c|}{ Clopidogrel } & \multicolumn{2}{|c|}{ Placebo } \\
\hline & & & & & & & $>5 \mathrm{~d}$ & $<\mathbf{5 ~ d}$ & $>\mathbf{5} \mathbf{d}$ & $<\mathbf{5} \mathbf{d}$ \\
\hline ACUITY $^{12}$ & $\mathrm{RCT}^{*}$ & 2009 & $2003-2005$ & NSTE-ACS & 100 & 12.7 & 249 & 524 & 747 & \\
\hline CLARITY-TIMI- $28^{4}$ & $\mathrm{RCT}^{*}$ & 2007 & 2003-2004 & STE-ACS & 100 & NR & 31 & 35 & 32 & 38 \\
\hline CRUSADE $^{5}$ & Observational & 2006 & $2003-2004$ & NSTE-ACS & 100 & NR & 113 & 739 & 180 & 1826 \\
\hline Akowuah $^{13}$ & $\mathrm{RCT}$ & 2005 & $2002-2003$ & NSTE-ACS & 100 & 0 & 24 & 25 & NR & NR \\
\hline CURE $^{11}$ & $\mathrm{RCT}^{*}$ & 2004 & $1998-2000$ & NSTE-ACS & 48 & NR & 456 & 436 & 454 & 476 \\
\hline
\end{tabular}

$C A B G$, Coronary artery bypass grafting; OPCAG, off-pump coronary artery bypass grafting; ACUITY, Acute Catheterization and Urgent Intervention Triage strategY; $R C T$, randomized controlled trial; NSTE-ACS, non-ST-elevation acute coronary syndrome; CLARITY-TIMI-28, Clopidogrel as Adjunctive Reperfusion Therapy-Thrombolysis in Myocardial Infarction 28; STE-ACS, ST-elevation acute coronary syndrome; NR, not reported; CRUSADE, Can Rapid Risk Stratification of Unstable Angina Patients Suppress Adverse Outcomes With Early Implementation of the ACC/AHA [American College of Cardiology/American Heart Association] Guidelines; CURE, Clopidogrel in Unstable Angina to Prevent Recurrent Events. *Retrospective subgroup analysis of larger RCT. †Either placebo or no medication. 


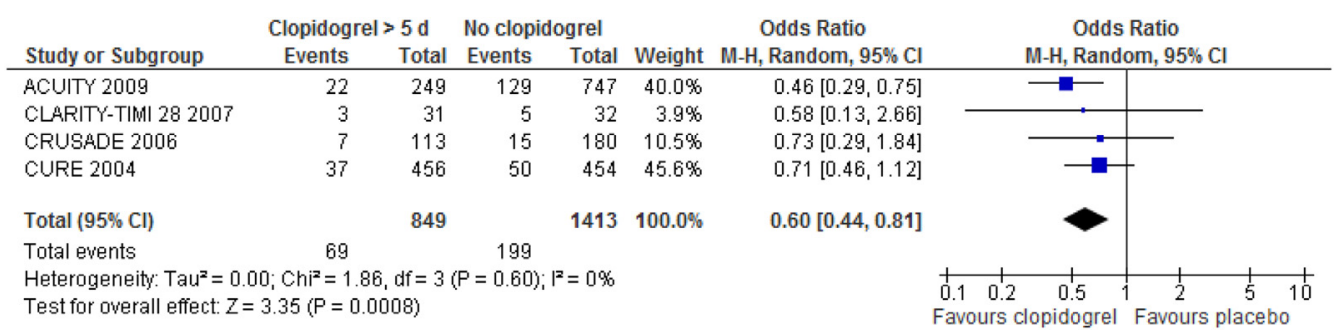

FIGURE 2. Forest plot of the odds ratio of the composite endpoint of mortality and myocardial infarction after $>5$ days clopidogrel washout versus no clopidogrel before coronary artery bypass grafting. The estimate of the odds ratio of each trial corresponds to the middle of the squares, and the horizontal line shows the $95 \%$ confidence interval $(C I)$. On each line, the numbers of events as a fraction of the total number randomized are shown for both treatment groups. For each subgroup, the sum of the statistics, along with the summary odds ratio, is represented by the middle of the solid diamonds. A test of heterogeneity between the trials within a subgroup is given below the summary statistics. $M-H$, Mantel-Haenszel; ACUITY, Acute Catheterization and Urgent Intervention Triage strategY; CLARITY-TIMI, Clopidogrel as Adjunctive Reperfusion Therapy-Thrombolysis in Myocardial Infarction 28; CRUSADE, Can Rapid Risk Stratification of Unstable Angina Patients Suppress Adverse Outcomes With Early Implementation of the ACC/AHA [American College of Cardiology/American Heart Association] Guidelines; CURE, Clopidogrel in Unstable Angina to Prevent Recurrent Events.

$3.2 \%$; OR, 0.47; 95\% CI, 0.25-0.91; $P=.03 ; \mathrm{I}^{2}=0 \%$; Figure 3); a lower incidence of major bleeding (19.7\% vs $30.2 \%$; OR, $0.71 ; 95 \%$ CI, $0.51-0.98 ; \quad P=.04$; $\mathrm{I}^{2}=38 \%$; Figure 4); and a lower incidence of the composite endpoint that included mortality and myocardial infarction, ${ }^{5,13}$ as well as recurrent ischemia, ${ }^{4}$ stroke, ${ }^{11}$ and emergency revascularization ${ }^{12}(7.9 \%$ vs 9.7\%; OR, 0.68; 95\% CI, 0.50-0.92; $P=.01 ; \mathrm{I}^{2}=0 \%$; Figure 5). The difference in the all-cause mortality rates between the 2 treatment groups was not statistically significant $(3.1 \%$ vs $4.0 \%$; OR, $0.77 ; 95 \%$ CI, $\left.0.29-2.07 ; P=.61 ; \mathrm{I}^{2}=47 \%\right)$. Separate analyses using a fixed effect model did not alter the significant statistical findings.

\section{DISCUSSION}

CABG remains the preferred treatment modality for selected patients presenting with ischemic heart disease, particularly in the context of total arterial revascularization according to recent evidence. ${ }^{14-16}$ When considering the postoperative bleeding outcomes of an irreversible antiplatelet agent such as clopidogrel, the timing of medication cessation before CABG is paramount. Previous studies have generalized outcomes after categorizing patients to "clopidogrel" versus "no clopidogrel," without emphasis on the washout period. $^{11,12,17}$ In the Acute Catheterization and Urgent Intervention Triage strategY study, Ebrahimi and colleagues $^{12}$ reported that patients who were given clopidogrel before CABG had a significantly reduced 30-day composite incidence of ischemia but not of increased post-CABG major bleeding. However, when the data were stratified according to the timing of clopidogrel cessation before $\mathrm{CABG}$, the patients who had $>5$ days of washout were significantly less likely to undergo transfusion or to develop composite ischemia compared with patients who underwent CABG within 5 days of their last clopidogrel dose. ${ }^{12}$ One potential explanation for this is that the patients who underwent $\mathrm{CABG}<5$ days after clopidogrel might have represented a cohort who were at greater risk and more unstable. However, this hypothesis was refuted by the Can Rapid Risk Stratification of Unstable Angina Patients Suppress Adverse Outcomes With Early Implementation of the ACC/AHA [American College of Cardiology/American Heart Association] Guidelines (CRUSADE) study, which reported that

\begin{tabular}{|c|c|c|c|c|c|c|c|c|c|}
\hline \multirow[b]{2}{*}{ Study or Subgroup } & \multicolumn{2}{|c|}{ Clopidogrel > $5 \mathrm{~d}$} & \multicolumn{2}{|c|}{ Clopidogrel $<5 \mathrm{~d}$} & \multirow[b]{2}{*}{ Weight } & \multirow{2}{*}{$\begin{array}{c}\text { Odds Ratio } \\
\mathrm{M}-\mathrm{H} \text {, Random, } 95 \% \mathrm{Cl}\end{array}$} & \multirow{2}{*}{\multicolumn{3}{|c|}{$\begin{array}{c}\text { Odds Ratio } \\
\text { M-H, Random, } 95 \% \mathrm{Cl}\end{array}$}} \\
\hline & Events & Total & Events & Total & & & & & \\
\hline ACUITY 2009 & 2 & 249 & 8 & 524 & $17.5 \%$ & $0.52[0.11,2.48]$ & & & \\
\hline Akowuah 2005 & 3 & 24 & 3 & 25 & $14.5 \%$ & $1.05[0.19,5.78]$ & & & \\
\hline CLARITY-TIMI 282007 & 2 & 31 & 4 & 35 & $13.5 \%$ & $0.53[0.09,3.14]$ & & & \\
\hline CURE 2004 & 7 & 456 & 18 & 436 & $54.4 \%$ & $0.36[0.15,0.88]$ & & & \\
\hline Total $(95 \% \mathrm{Cl})$ & & 760 & & 1020 & $100.0 \%$ & $0.47[0.25,0.91]$ & & & \\
\hline Total events & 14 & & 33 & & & & & & \\
\hline $\begin{array}{l}\text { Heterogeneity: Tau }{ }^{2}=0 \\
\text { Test for overall effect: } z\end{array}$ & $\begin{array}{l}0 ; \mathrm{Chi}^{2}=1 \\
2.24(\mathrm{P}=0\end{array}$ & $d f=30$ & $P=0.75) ;$ & & & & $\begin{array}{ccc}0.1 & 0.2 & 0.5\end{array}$ & $\begin{array}{c}2 \\
\text { Favours }\end{array}$ & $\begin{array}{cc}5 & 10 \\
\text { idogrel }<5 d\end{array}$ \\
\hline
\end{tabular}

FIGURE 3. Forest plot of the odds ratio of reoperation after $>5$ days of clopidogrel washout versus $<5$ days washout before coronary artery bypass grafting. The estimate of the odds ratio of each trial corresponds to the middle of the squares, and the horizontal line shows the $95 \%$ confidence interval (CI). On each line, the numbers of events as a fraction of the total number randomized are shown for both treatment groups. For each subgroup, the sum of the statistics, along with the summary odds ratio, is represented by the middle of the solid diamonds. A test of heterogeneity between the trials within a subgroup is given below the summary statistics. M-H, Mantel-Haenszel; ACUITY, Acute Catheterization and Urgent Intervention Triage strategY; CLARITY-TIMI, Clopidogrel as Adjunctive Reperfusion Therapy-Thrombolysis in Myocardial Infarction 28; CURE, Clopidogrel in Unstable Angina to Prevent Recurrent Events. 


\begin{tabular}{|c|c|c|c|c|c|c|c|c|c|}
\hline \multirow[b]{2}{*}{ Study or Subgroup } & \multicolumn{2}{|c|}{ Clopidogrel > $5 \mathrm{~d}$} & \multicolumn{2}{|c|}{ Clopidogrel $<5 d$} & \multirow[b]{2}{*}{ Weight } & \multirow{2}{*}{$\begin{array}{c}\text { Odds Ratio } \\
\text { M-H, Random, } 95 \% \mathrm{Cl}\end{array}$} & \multirow{2}{*}{\multicolumn{3}{|c|}{$\begin{array}{c}\text { Odds Ratio } \\
\text { M-H, Random, } 95 \% \mathrm{Cl} \\
\end{array}$}} \\
\hline & Events & Total & Events & Total & & & & & \\
\hline ACUITY 2009 & 116 & 249 & 273 & 524 & $43.2 \%$ & $0.80[0.59,1.08]$ & $\rightarrow$ & & \\
\hline CLARITY-TIMI| 282007 & 2 & 31 & 4 & 35 & $3.3 \%$ & $0.53[0.09,3.14]$ & & & \\
\hline CRUSADE 2006 & 29 & 113 & 205 & 739 & $29.9 \%$ & $0.90[0.57,1.41]$ & $\longrightarrow$ & - & \\
\hline CURE 2004 & 20 & 456 & 42 & 436 & $23.6 \%$ & $0.43[0.25,0.75]$ & $=$ & & \\
\hline Total $(95 \% \mathrm{Cl})$ & & 849 & & 1734 & $100.0 \%$ & $0.71[0.51,0.98]$ & & & \\
\hline Total events & 167 & & 524 & & & & & & \\
\hline $\begin{array}{l}\text { Heterogeneity: Tau }{ }^{2}=0 \text {. } \\
\text { Test for overall effect: } Z=\end{array}$ & $\begin{array}{l}4 ; \mathrm{Chi}^{2}=4 \\
2.06(\mathrm{P}=0\end{array}$ & $d f=30$ & $P=0.18) ;$ & $38 \%$ & & & $\begin{array}{ccc}0.1 & 0.2 & 0.5 \\
\text { Favours clopidogrel } & >5 \mathrm{~d}\end{array}$ & $\begin{array}{l}1 \\
1 \\
\text { Favours }\end{array}$ & $\begin{array}{ll}5 & 1 \\
\text { pidogrel }\end{array}$ \\
\hline
\end{tabular}

FIGURE 4. Forest plot of the odds ratio of major bleeding after $>5$ days of clopidogrel washout versus $<5$ days washout before coronary artery bypass grafting. The estimate of the odds ratio of each trial corresponds to the middle of the squares, and the horizontal line shows the $95 \%$ confidence interval (CI). On each line, the numbers of events as a fraction of the total number randomized are shown for both treatment groups. For each subgroup, the sum of the statistics, along with the summary odds ratio, is represented by the middle of the solid diamonds. A test of heterogeneity between the trials within a subgroup is given below the summary statistics. M-H, Mantel-Haenszel; ACUITY, Acute Catheterization and Urgent Intervention Triage strategY; CLARITY-TIMI, Clopidogrel as Adjunctive Reperfusion Therapy-Thrombolysis in Myocardial Infarction 28; CRUSADE, Can Rapid Risk Stratification of Unstable Angina Patients Suppress Adverse Outcomes With Early Implementation of the ACC/AHA [American College of Cardiology/American Heart Association] Guidelines; CURE, Clopidogrel in Unstable Angina to Prevent Recurrent Events.

patients who underwent CABG after $>5$ days of washout actually had a higher risk profile, including previous revascularization, previous stroke, diabetes, renal failure, and acute presenting features such as congestive heart failure, tachycardia, and elevated cardiac enzymes. ${ }^{5}$ The investigators of the CRUSADE trial hypothesized that more stable patients might have undergone early CABG owing to economic restraints or a lack of appreciation of the bleeding outcomes associated with clopidogrel close to $\mathrm{CABG}$.

A number of guidelines have been published to assist clinicians in making decisions regarding the prescription of clopidogrel for patients who present with ACS (Table 2). Although a relative consensus has been reached for patients who undergo elective CABG to have a delay of 5 to 7 days after the last clopidogrel dose, the recommendations for patients who require urgent $\mathrm{CABG}$ are less clear. These have ranged from a waiting period of 5 to 7 days to continuing clopidogrel until surgery. ${ }^{6-10}$ The American College of Cardiology Foundation/American Heart
Association guidelines have recommended clopidogrel cessation for $\geq 1$ day before urgent $C A B G$ and stated that it would be reasonable to perform urgent surgery within 5 days of clopidogrel treatment. ${ }^{15}$ Similarly, the Society of Thoracic Surgeons has recommended a delay of 1 or 2 days for patients requiring urgent $\mathrm{CABG} .{ }^{18} \mathrm{In}$ addition, a previous meta-analysis that did not categorize the studies according to the washout period of clopidogrel concluded that patients presenting with ACS should proceed to surgery without delay for a clopidogrel-free interval. ${ }^{17}$

The present meta-analysis identified outcomes according to the timing of clopidogrel cessation in relation to CABG. Despite the widespread prescription of clopidogrel in the clinical setting, it was surprising to find only 5 relevant studies with sufficient data to analyze in the existing literature. Similar to individual trials, we found that patients who were given clopidogrel with $>5$ days clearance before surgery had a significantly lower composite endpoint, including mortality and myocardial

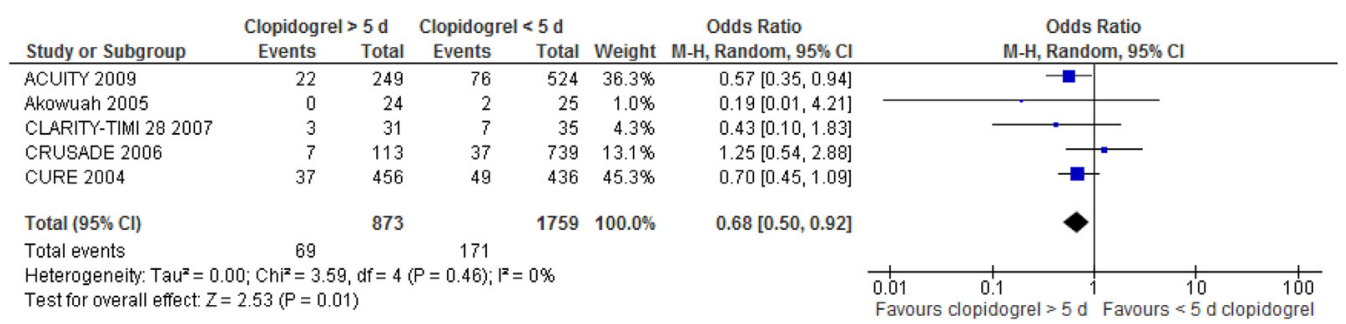

FIGURE 5. Forest plot of the odds ratio of the composite endpoint of mortality and myocardial infarction after $>5$ days clopidogrel washout versus $<5$ days washout before coronary artery bypass grafting. The estimate of the odds ratio of each trial corresponds to the middle of the squares, and the horizontal line shows the $95 \%$ confidence interval $(C I)$. On each line, the numbers of events as a fraction of the total number randomized are shown for both treatment groups. For each subgroup, the sum of the statistics, along with the summary odds ratio, is represented by the middle of the solid diamonds. A test of heterogeneity between the trials within a subgroup is given below the summary statistics. $M$ - $H$, Mantel-Haenszel; ACUITY, Acute Catheterization and Urgent Intervention Triage strategY; CLARITY-TIMI, Clopidogrel as Adjunctive Reperfusion Therapy-Thrombolysis in Myocardial Infarction 28; CRUSADE, Can Rapid Risk Stratification of Unstable Angina Patients Suppress Adverse Outcomes With Early Implementation of the ACC/AHA [American College of Cardiology/American Heart Association] Guidelines; CURE, Clopidogrel in Unstable Angina to Prevent Recurrent Events. 
TABLE 2. A summary of guideline recommendations for the prescription of clopidogrel for patients before coronary artery bypass grafting

\begin{tabular}{|c|c|c|c|}
\hline Guideline & Year & Elective CABG & Urgent CABG \\
\hline Society of Thoracic Surgeons & 2012 & $\begin{array}{l}\text { Cease "a few days" before } \\
\text { elective CABG }\end{array}$ & "A delay of a day or two is reasonable" \\
\hline American College of Chest Physicians & 2012 & Cease $\geq 5 \mathrm{~d}$ & $\begin{array}{l}\text { No specific recommendations, anticipate use of } \\
\text { platelet transfusion and antifibrinolytic drugs if } \\
\text { clopidogrel given }<5 \mathrm{~d} \text { before CABG }\end{array}$ \\
\hline $\begin{array}{l}\text { American College of Cardiology Foundation/ } \\
\text { American Heart Association }\end{array}$ & 2011 & Cease $\geq 5 \mathrm{~d}$ & $\begin{array}{l}\text { Cease } \geq 1 \mathrm{~d} ; \text { " "reasonable to perform CABG } \\
\quad<5 \mathrm{~d} \text { after clopidogrel" }\end{array}$ \\
\hline Canadian Cardiovascular Society & 2009 & Cease $5-7 \mathrm{~d}$ & $\begin{array}{l}\text { If at high risk of fatal ischemic event or with high-risk } \\
\text { coronary anatomy, continue clopidogrel; if high } \\
\text { ischemic risk and high bleeding risk, cease at } 3-5 \mathrm{~d}\end{array}$ \\
\hline European Association for Cardio-Thoracic Surgery & 2008 & $5-7 \mathrm{~d}$ "if condition allows" & $5-7 \mathrm{~d}$ "if condition allows" \\
\hline
\end{tabular}

$C A B G$, Coronary artery bypass grafting.

infarction, compared with patients not treated with clopidogrel at all. These 2 groups also did not have a statistically significant difference in the incidences of reoperation, all-cause mortality, or major bleeding. However, when patients with $>5$ days of washout were compared with patients who underwent CABG within 5 days of clopidogrel treatment, the patients with the shorter washout period were almost twice as likely to require reoperation and were significantly more likely to experience major bleeding or a combined endpoint that included mortality, myocardial infarction, stroke, and revascularization. These findings were not reported in the individual trials or previous meta-analyses and underscored the importance of categorizing patients who were allocated to the clopidogrel group according to their duration of medication cessation.

A number of limitations to our study should be acknowledged, and the results should be interpreted with caution. First, the patient inclusion criteria differed among the studies, and the presenting features included ST-elevation ACS and non-ST-elevation ACS. However, the exclusion of studies involving patients with stable coronary artery disease aimed to target a specific study population in our analysis. Second, the surgical techniques could have varied among institutions, and the reporting of off-pump CABG was limited, although it has been previously shown to result in fewer bleeding complications for patients treated with clopidogrel. ${ }^{19,20}$ Third, the endpoints and definitions varied among the studies, with the composite endpoint including mortality and myocardial infarction, ${ }^{5,13}$ as well as stroke, ${ }^{11}$ recurrent ischemia, ${ }^{4}$ and urgent revascularization. ${ }^{12}$ However, no significant heterogeneity was detected by our statistical assessment.

To interpret the results reported in the present study in the context of more novel $\mathrm{P} 2 \mathrm{Y}_{12}$ receptor antagonists, such as prasugrel, ticagrelor, and cangrelor, it is important to acknowledge the lack of robust clinical data on the perioperative effects of these contemporary agents after
CABG. The PLATelet inhibition and patient Outcomes (PLATO) and Clopidogrel in Non-ST-Segment Elevation Myocardial Infarction-2 (DISPERSE-2) trials compared ticagrelor with clopidogrel but varied in their trial design and endpoint definitions. ${ }^{21,22}$ The PLATO trial analyzed 1261 patients who had undergone CABG within 7 days of medication cessation and concluded that patients treated with ticagrelor had a significantly lower risk of overall and cardiovascular death compared with those receiving clopidogrel. However, no significant differences were found in the incidence of major bleeding. ${ }^{21}$ Similarly, post hoc analysis of the DISPERSE-2 trial found a trend, but no statistical significance, favoring ticagrelor over clopidogrel for bleeding outcomes. ${ }^{22}$ A subgroup analysis of the Trial to Assess Improvement in Therapeutic Outcomes by Optimizing Platelet Inhibition with Prasugrel-Thrombolysis In Myocardial Infarction 38 (TRITON-TIMI 38) study compared patients who were prescribed prasugrel versus clopidogrel before isolated $\mathrm{CABG}$ and found that patients treated with prasugrel were more likely to experience greater chest drain bleeding, platelet transfusion, and reoperation but fewer perioperative deaths. $^{23}$ Finally, the BRIDGE investigators compared cangrelor and placebo agents in a RCT of or patients who had presented with ACS or undergone coronary stent implantation before CABG. ${ }^{24}$ The results of that trial suggested that the differences in major bleeding between the 2 treatment arms were not significant, but patients treated with cangrelor were more likely to have minor bleeding. ${ }^{24}$ Overall, data are currently insufficient in the published studies to quantitatively meta-analyze novel $\mathrm{P}_{2} \mathrm{Y}_{12}$ inhibitors, and future RCTs assessing the safety and efficacy of antiplatelet agents should aim to predefine CABG-related outcomes rather than retrospectively performing subgroup analyses. In the present clinical setting, patients might benefit from platelet activity measurements that can predict increased risks of postoperative bleeding and transfusion. ${ }^{25}$ 


\section{CONCLUSIONS}

The results from the present meta-analysis suggest that patients who present with ACS should be treated with dual antiplatelet therapy that includes clopidogrel. However, for patients subsequently referred for CABG, a minimum washout period of 5 days could be observed in clinically suitable situations to minimize the incidence of perioperative bleeding and bleeding-related complications. Such complications include repeat sternotomy and re-exploration, which has been associated with a 4.5 -fold increase in perioperative mortality. ${ }^{25}$ The longer duration of preoperative hospitalization could have economic implications for patients who need to be monitored as an inpatient before CABG. However, evidence from our study has suggested that they are at a lower risk of mortality and recurrent ischemia compared with patients expedited to surgery.

\section{References}

1. Michelson E, Morganroth J, Torosian M, MacVaugh H III. Relation of preoperative use of aspirin to increased mediastinal blood loss after coronary artery bypass graft surgery. J Thorac Cardiovasc Surg. 1978;76:694-7.

2. Torosian M, Michelson E, Morganroth J, MacVaugh H III. Aspirin- and coumadin-related bleeding after coronary-artery bypass graft surgery. Ann Intern Med. 1978;89:325-8

3. Sabatine M, Cannon C, Michael Gibson M, López-Sendón J, Montalescot G, Theroux $\mathrm{P}$, et al. Addition of clopidogrel to aspirin and fibrinolytic therapy for myocardial infarction with ST-segment elevation. N Engl J Med. 2005;352: 1179-89.

4. McLean D, Sabatine M, Guo W, McCabe C, Cannon C. Benefits and risks of clopidogrel pretreatment before coronary artery bypass grafting in patients with ST-elevation myocardial infarction treated with fibrinolytics in CLARITY-TIMI 28. J Thromb Thrombolysis. 2007;24:85-91.

5. Mehta R, Roe M, Mulgund J, Ohman E, Cannon C, Gibler W, et al. Acute clopidogrel use and outcomes in patients with non-ST-segment elevation acute coronary syndromes undergoing coronary artery bypass surgery. J Am Coll Cardiol. 2006;48:281-6.

6. Ferraris V, Saha S, Oestreich J, Song H, Rosengart T, Reece T, et al. 2012 Update to the Society of Thoracic Surgeons guideline on use of antiplatelet drugs in patients having cardiac and noncardiac operations. Ann Thorac Surg. 2012;94: 1761-81.

7. Douketis J, Spyropoulos A, Spencer F, Mayr M, Jaffer A, Eckman M, et al. Perioperative management of antithrombotic therapy: antithrombotic therapy and prevention of thrombosis, 9th ed: American College of Chest Physicians Evidence-Based Clinical Practice Guidelines. Chest. 2012;141: e326S-50S.

8. Hillis L, Smith P, Anderson J, Bittl J, Bridges C, Byrne J, et al. 2011 ACCF/AHA guideline for coronary artery bypass graft surgery: executive summary: a report of the American College of Cardiology Foundation/American Heart Association Task Force on Practice Guidelines. J Thorac Cardiovasc Surg. 2012;143:4-34.

9. Fitchett D, Eikelboom J, Fremes S, Mazer D, Singh S, Bittira B, et al. Dual antiplatelet therapy in patients requiring urgent coronary artery bypass grafting surgery: a position statement of the Canadian Cardiovascular Society. Can J Cardiol. 2009;25:683-9.

10. Dunning J, Versteegh M, Fabbri A, Pavie A, Kolh P, Lockowandt U, et al. Guideline on antiplatelet and anticoagulation management in cardiac surgery. Eur J Cardiothorac Surg. 2008;34:73-92.

11. Fox K, Mehta S, Peters R, Zhao F, Lakkis N, Gersh B, et al. Benefits and risks of the combination of clopidogrel and aspirin in patients undergoing surgical revascularization for non-ST-elevation acute coronary syndrome. Circulation. 2004;110:1202-8.

12. Ebrahimi R, Dyke C, Mehran R, Manoukian S, Feit F, Cox D, et al. Outcomes following pre-operative clopidogrel administration in patients with acute coronary syndromes underoging coronary artery bypass surgery. J Am Coll Cardiol. 2009;53:1965-72.

13. Akowuah E, Shrivastava V, Jamnadas B, Hopkinson D, Sarkar P, Storey R, et al. Comparison of two strategies for the management of antiplatelet therapy during urgent surgery. Ann Thorac Surg. 2005;80:149-52.

14. Cao C, Manganas C, Bannon P, Vallely M, Yan T. Drug-eluting stents versus coronary artery bypass graft surgery in left main coronary artery disease: a meta-analysis of early outcomes from randomized and nonrandomized studies. J Thorac Cardiovasc Surg. 2013;145:738-47.

15. Weiss A, Zhao S, Tian D, Taggart D, Yan T. A meta-analysis comparing bilateral internal mammary artery with left internal mammary artery for coronary artery bypass grafting. Ann Cardiothorac Surg. 2013;2:390-400.

16. Cao C, Manganas C, Horton M, Bannon P, Munkholm-Larsen S, Ang S, et al. Angiographic outcomes of radial artery versus saphenous vein in coronary artery bypass graft surgery: a meta-analysis of randomized controlled trials. J Thorac Cardiovasc Surg. 2013;146:255-61.

17. Nijjer S, Watson G, Athanasiou T, Malik I. Safety of clopidogrel being continued until the time of coronary artery bypass grafting in patients with acute coronary syndrome: a meta-analysis of 34 studies. Eur Heart J. 2011;32: 2970-88.

18. Cao C, Ang S, Wolak K, Peeceeyen S, Bannon P, Yan T. A meta-analysis of randomized controlled trials on mid-term angiographic outcomes for radial artery versus saphenous vein in coronary artery bypass graft surgery. Ann Cardiothorac Surg. 2013;2:401-7.

19. Woo Y, Grand T, Valettas N. Off-pump coronary artery bypass grafting attenuates postoperative bleeding associated with preoperative clopidogrel administration. Heart Surg Forum. 2003;6:282-5.

20. Song S, Youn Y, Yi G, Lee S, Yoo K. Effects of continuous administration of clopidogrel before off-pump coronary artery bypass grafting in patients with acute coronary syndrome. Circ J. 2008;72:626-32.

21. Held C, Bassand J, Becker R, Cannon C, Claeys M, Harrington R, et al. Ticagrelor versus clopidogrel in patients with acute coronary syndromes undergoing coronary artery by-pass surgery: results from the PLATO trial. J Am Coll Cardiol. 2011;57:672-84.

22. Husted S, Harrington R, Cannon C, Storey R, Mitchell P, Emanuelsson H. Bleeding risk with AZD6140, a reversible P2Y12 receptor antagonist, vs. clopidogrel in patients undergoing coronary artery bypass grafting in the DISPERSE2 trial. Int J Clin Pract. 2009;63:537-9.

23. Smith P, Goodnough L, Levy J, Poston R, Short M, Weerakkody G, et al. Mortality benefit with prasugrel in the TRITON-TIMI 38 coronary artery bypass grafting cohort. J Am Coll Cardiol. 2012;60:388-96.

24. Angiolillo D, Firstenberg M, Price M, Tummala P, Hutyra M, Welsby I, et al. Bridging antiplatelet therapy with cangrelor in patients undergoing cardiac surgery: a randomized controlled trial. JAMA. 2012;307:265-74.

25. Rosengart T, Romeiser J, White L, Fratello A, Fallon E, Senzel L, et al. Platelet activity measured by a rapid turnaround assay identifies coronary artery bypass grafting patients at increased risk for bleeding and transfusion complications after clopidogrel administration. J Thorac Cardiovasc Surg. 2013; 146:1259-66.e1; discussion 66. 